


\title{
Qualitative exposure assessment for Salmonella spp. in shell eggs produced on the island of Ireland
}

\author{
Laura Murchie $^{\text {a }}$, Bin Xia ${ }^{\text {b }}$, Robert H. Madden ${ }^{\text {a,c,* }}$, Paul Whyte ${ }^{\text {b }}$, Louise Kelly ${ }^{\text {d,e }}$ \\ a Food Science Department, Queen's University of Belfast, Belfast, United Kingdom \\ ${ }^{\mathrm{b}}$ Centre for Food Safety, School of Agriculture, Food Science and Veterinary Medicine, University College Dublin, Dublin, Ireland \\ ${ }^{\mathrm{c}}$ Food Microbiology Branch, Agri-Food and Biosciences Institute, Belfast, United Kingdom \\ d Department of Statistics and Modelling Science, University of Strathclyde, Glasgow, United Kingdom \\ e Centre for Epidemiology and Risk Analysis, Veterinary Laboratories Agency, New Haw, Addlestone, Surrey, United Kingdom
}

\section{Keywords:}

Exposure assessment

Salmonella

Eggs

Ireland

\begin{abstract}
A B S T R A C T
A qualitative exposure assessment for Salmonella in eggs produced on the island of Ireland was developed. The assessment was divided into three main modules (production and packing, distribution and storage, and preparation and consumption), and each of these stages into defined steps in the exposure pathway. In the production and packing stage the initial prevalences of Salmonella in the contents and on the shell of eggs were estimated to be negligible and low respectively. Numbers of Salmonella both in and on eggs were estimated to be low. At each subsequent step in the pathway, qualitative assessments were made of the impact of events on the probability and level of Salmonella contamination on the shells and in the contents of eggs. At the end of each module assessments were combined to give an overall probability and level of Salmonella contamination. In the first two modules the assessment focused on the effect of the duration and temperature of storage on yolk membrane integrity and the likelihood of shell penetration. During the final stage the influence of factors such as safe handling procedures, pooling practices, consumption patterns and the effectiveness of cooking, on the prevalence and level of Salmonella contamination in a food item at time of consumption was assessed. The outcome of this assessment was an estimate of a low probability and level of Salmonella contamination of egg containing foods, prepared with eggs produced on the island of Ireland.
\end{abstract}

\section{Introduction}

The late 1980s saw dramatic rises in the number of reported human cases of Salmonella Enteritidis in the United Kingdom (UK) and much of western Europe (Cogan and Humphrey, 2003; Rodrigue et al., 1990). The role of eggs in this pandemic has been well documented (Coyle et al., 1988; Mawer et al., 1989; Cowden et al., 1989a,b; de Louvois, 1993a,b). Unlike the majority of salmonellae, S. Enteritidis is able to colonise the reproductive tissues of birds (Okamura et al., 2001). For this reason, although a wide range of serovars are isolated from eggshells, only a few invasive serotypes, principally $S$. Enteritidis, are commonly isolated from the contents of clean intact eggs (Paul and Batchelor, 1988; Humphrey et al., 1989a; Gast and Beard, 1990; Humphrey et al., 1991; de Louvois 1993b). Legislation, industry codes of practice and quality assurance schemes for the control of Salmonella in laying flocks were introduced in the late 1990s in both the UK and Ireland. The success of these controls has been measured by the

\footnotetext{
* Corresponding author. Food Microbiology Branch, Agri-Food and Biosciences Institute, Newforge Lane, Belfast, BT9 5PX, , United Kingdom. Tel.: +44 2890255312 ; fax: +442890255009.

E-mail address: r.madden@qub.ac.uk (R.H. Madden).
}

reduction in Salmonella prevalence associated with shell eggs reported in recent surveys (Murchie et al., 2007; Anonymous, 2004a; Anonymous, 2003a) and the decline in the incidence of human salmonellosis in the Republic of Ireland (Foyle et al., 2004) and the UK (Anonymous, 2006a,b,c). The aim of this study was to provide a qualitative assessment of the risk of exposure to Salmonella from shell eggs produced on the island of Ireland, in the light of the changed circumstances.

Microbiological risk assessment (MRA) is an important tool in the management of food safety risks and since the publication of the Codex Alimentarius Commission (CAC) guidelines (Anonymous, 1999a), assessments for several pathogens in various food products have been developed, including $S$. enteritidis in shell eggs (Whiting et al., 2000; Hope et al., 2002) and pasteurised liquid eggs (Whiting \& Buchanan, 1997); Salmonella Typhimurium in Danish dry cured pork sausages (Alban et al., 2002); and Salmonella in whole chickens (Oscar, 2004). As outlined by the CAC (Anonymous, 1999a), MRA can be divided into 4 stages: hazard identification, exposure assessment, hazard characterization and risk characterization. Within this frame work, the exposure assessment tracks the pathogen from the farm to the point of consumption, taking account of the initial load, survival, growth, death and cross contamination. Combining these types of 
pathogen data with consumption data then yields estimates of the probability and level of exposure, for example, per serving or per year.

MRAs can be either qualitative or quantitative. In qualitative assessments, levels of risk are classified using terms such as low, moderate and high. These classifications are generally based on an evaluation of the available data using a pre defined framework together with expert judgement. As suggested by Clough et al. (2006), this approach enables rapid identification of the exposure pathway and areas of available, and sparse data, and is more appropriate than quantitative assessment when data are sparse. In addition, qualitative assessment provides a preliminary indication of levels of risk that can be used to guide risk managers.

In this paper we present a qualitative exposure assessment for Salmonella spp. in shell eggs produced on the island of Ireland. This assessment will be used to inform egg producers and risk managers of likely levels of risk and highlight future data requirements.

\section{Materials and methods}

\subsection{Exposure pathway}

The exposure pathway consists of 3 modules: a, production and packing, b, distribution and storage and c, preparation and consump tion. Each module is further divided into steps representing defined stages in the farm to fork chain (Fig. 1). The first module, production and packing, commences with an assessment of the initial prevalence (which can also be considered as the probability of occurrence) and levels of the pathogen on and within eggs. Changes to these variables were then assessed throughout the remaining modules as a result of bacterial dynamics, cross contamination and preparation and con sumption patterns.
As the potential for Salmonella growth in eggs is dependent on the site of contamination, the presence of Salmonella on the shell, and in the albumen and yolk, were considered separately at each stage. Salmonella may not be restricted to its initial deposition site; Salmonella on the shell surface may contaminate the contents by penetrating the shell and associated membranes (Bradshaw et al., 1990; Gast and Beard, 1990; Humphrey et al., 1991), and over time the integrity of the yolk membrane can decline, allowing cells in the albumen access to the yolk (Humphrey and Whitehead, 1993). Therefore the likelihood of Salmonella either penetrating the shell or the yolk membrane was also included until the preparation and consumption module, where contamination of the contents as a whole is considered, along with the likelihood of Salmo nella from the shell contaminating food during the breaking of eggs (Fig. 1). It is worth mentioning that any organism present on the shell could also lead to infection as a result of cross contamination to, e.g. hands or uncooked food. This is not considered in this assessment.

The exposure assessment concludes in a qualitative estimation of the probability and level of exposure to Salmonella following the ingestion of a single serving of an egg containing food.

\subsection{Qualitative evaluations}

At each stage of the exposure pathway, the factors affecting the probability and levels of Salmonella contamination were considered and classified following the qualitative scheme of Moutou et al. (2001):

- Negligible probability so low as to be effectively discounted, or event likely only under rare circumstances.

- Low event may occur in some cases.

- Moderate occurrence is a possibility.

- High event is a likely to occur.

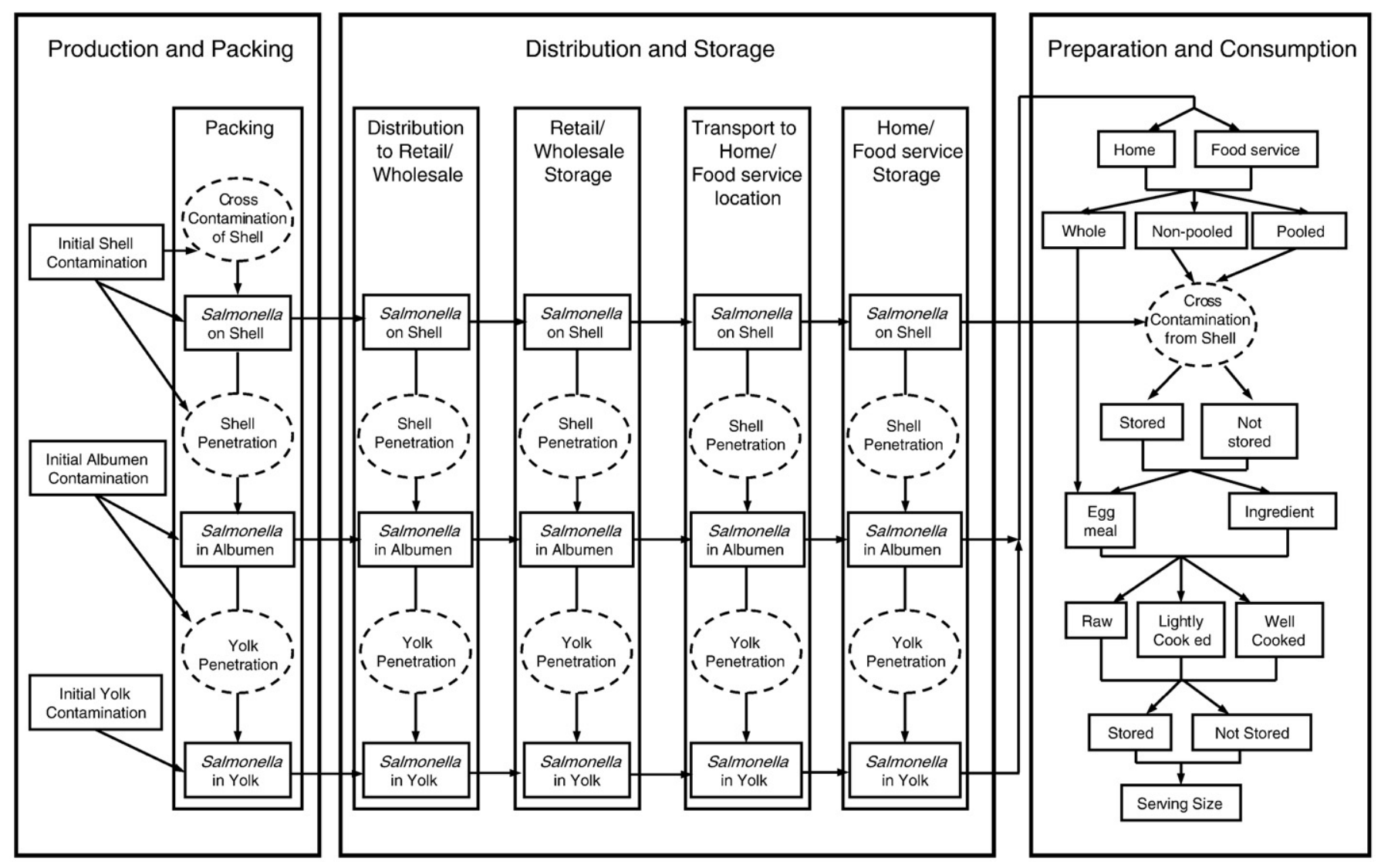

Fig. 1. Flowchart summarising the exposure assessment pathway for Salmonella in shell eggs produced on the island of Ireland. 
These were then combined to give a probability and level for the end of each module. For instance, the probability of Salmonella being present on the shell of an egg at the time of lay was combined with the probability of cross contamination during production and packing to give the probability of contamination at the end of that stage. When combining two qualitative evaluations, the framework of Moutou et al. (2001) was again used. This matrix is appropriate because the model is additive at each stage; we are considering the addition or the removal of organisms rather than multiplying probabilities. It is important not to assign numerical values to these qualitative evaluations because they are inherently subjective.

\section{Results}

\subsection{Production and packing}

This module focuses on the prevalence and level of Salmonella contamination in eggs produced on the island of Ireland at the time of lay and the effect of environmental conditions on contamination from this time until the eggs leave the packing site.

\subsubsection{Salmonella control strategies in egg production on the island of Ireland}

In both the Republic of Ireland and Northern Ireland, Salmonella spp. in the egg production chain are controlled under the Zoonoses Directive (Council Directive 92/117/EEC). This directive provides for the implementation of salmonella control programmes by member states, although these differ in detail from state to state.

In the Republic of Ireland the directive is transposed into Irish law as S.I. No. 2 of 1996 (Anonymous, 1996) under which all hatcheries, poultry breeder farms (grandparent and parent farms) and laying flocks are monitored for Salmonella spp. and any flocks confirmed with $S$. Enteritidis or S. Typhimurium are slaughtered. In addition, both feed materials and compound feedingstuffs for poultry are tested for Salmonella spp. Treatment of laying flocks with vaccines, antibiotics or competitive exclusion type products is forbidden.

In addition to the directive, voluntary schemes are operated in both the Republic of Ireland and NI. In NI, the Lion Quality code of practice, which requires the vaccination of commercial layer flocks against $S$. Enteritidis, has been widely adopted (Anonymous, 2005a), with approximately $85 \%$ of UK egg production covered by the scheme. The scheme also covers aspects of animal welfare, hygiene, feed controls and traceability of eggs, hens and feed.

The Bord Bia Egg Quality Assurance Scheme (EQAS) is a voluntary programme in the Republic of Ireland which incorporates additional Salmonella spp. controls to those specified in the legislation. It also covers many aspects of egg production (hygiene, disease control and flock welfare) and packaging. During the production stage the salmonella controls are built around the sourcing of pre lay birds from approved sources with the relevant documentary evidence. Product identification and traceability are the key requirements at the packaging stage. The scheme reiterates the ban on the treatment of laying flocks with vaccines, antibiotics or competitive exclusion type products, hence the scheme differs significantly from that used in NI.

\subsubsection{Prevalence of Salmonella contaminated eggs in the island of Ireland}

Recent surveys of UK (Anonymous, 2004a) and Irish produced eggs (Anonymous, 2003a) on retail sale, Irish produced eggs collected from packing stations (Murchie et al., 2007), and eggs used by catering premises in the UK (Anonymous, 2007b; Elson et al., 2005) have reported lower prevalences (between 0 and $0.38 \%$ ) of Salmonella in eggs compared with earlier studies (Anonymous, 2001; de Louvois, 1993a,b) which reported prevalences of 0.99 and $0.92 \%$ respectively. These reductions are likely due to the introduction of legislation, industry codes of practice and quality assurance schemes to control Salmonella in laying flocks. Murchie et al. (2007) surveyed eggs produced on the island of Ireland in 2005 2006, and found no internally contaminated eggs, although Salmonella spp. were isolated from the shells of 2 out of 5018 samples of 6 eggs. These results indicate a negligible incidence of internal contamination and a low incidence of shell contamination of eggs produced on the island of Ireland. There was no statistically significant difference in the prevalence of salmonellae between eggs produced in Northern Ireland (2/2503 samples of 6 eggs positive for Salmonella) and those from the Republic of Ireland (0/2515 samples of 6 eggs positive for Salmonella), indicating the control strategies employed on the island of Ireland are equally effective in controlling Salmonella contamination (Murchie et al., 2007). Salmonella Infantis and Salmonella Montevideo were isolated from shells and these serovars are not associated with reproductive tract infections in birds, or commonly isolated from internal contents of eggs. Little correlation is often reported in serotype or prevalence of Salmonella isolated from the shell and contents of eggs (Humphrey, 1994; De Buck et al., 2004), and several studies, including four recent surveys of eggs conducted in the island of Ireland and the UK (Anonymous, 2007b; Murchie et al., 2007; Anonymous, 2004a; Davies and Breslin, 2004), found a higher prevalence of shell contamination compared to that of the egg contents. Two of these surveys reported no internal contamination of eggs while 14 out of 4753 (Anonymous, 2004a) and 2 out of 5018 (Murchie et al., 2007) samples of 6 eggs were positive for Salmonella. In the further two surveys, the contents were contaminated in 3 out of 92 (Davies and Breslin, 2004) and 1 out of 6 (Anonymous, 2007b) batches of 6 eggs found to be positive for Salmonella.

\subsubsection{Salmonella on shell surface}

The presence of salmonellae on the surface of eggshells may pose a risk to the public either by giving rise to internal contamination following shell penetration, or as a source of cross contamination during food preparation. We are not aware of any published data of numbers of Salmonella on the surface of naturally contaminated eggs. One study of the microbiology of shell eggs isolated, but did not enumerate, Salmonella on the shells of eggs. In the same study, counts of $E$. coli from shell rinses (total volume $30 \mathrm{ml} /$ per egg) were of the order of $5 \mathrm{cfu} / \mathrm{ml}$ (Musgrove et al., 2005). Based on this limited data, numbers of Salmonella on the surface of clean eggs were estimated to be low. Salmonella from the shells of contaminated eggs may be transferred to the shells of other eggs during packing, but given the low incidence of Salmonella contamination associated with eggshells the likelihood of this occurring was judged to be low.

Although it is generally accepted that under ambient conditions Salmonella on the surface of eggs rapidly die (Rizk et al., 1966; Baker, 1990), the reported prevalence of shell contamination is indicative that this is not always the case. $S$. Enteritidis has been isolated from between 8.8 and $20 \%$ of eggs, inoculated with $10^{2.5}$ $10^{4} \mathrm{cfu}$, after 20 days incubation at $25{ }^{\circ} \mathrm{C}$ (Messens et al., 2006) or 21 days incubation at $20^{\circ} \mathrm{C}$ (De Reu et al., 2006). Salmonella spp. have also been found on the shells of naturally contaminated Grade A eggs after 4 days storage at temperatures between 10 and $20^{\circ} \mathrm{C}$ (Murchie, unpublished data) and after 4 weeks at $2022{ }^{\circ} \mathrm{C}$ from eggs contaminated with excrement (Braun et al., 2002) and from eggs produced by inoculated hens (Methner et al., 1995). The survival of Salmonella on the surface of eggs is dependent on temperatures of storage (Humphrey, 1994) and may be increased by storage at low temperatures (Messens et al., 2006; Radkowski, 2002; Baker, 1990). Although low temperatures increase survival of Salmonella on the shell, contamination of the egg contents by these surface bacteria either occurs slowly (Messens et al., 2006) or does not occur under these conditions (Simmons et al., 1970).

\subsubsection{Penetration of eggshell}

Before the emergence of $S$. Enteritidis, shell penetration was considered the most common route for Salmonella contamination of 
egg contents (Simmons et al., 1970), and it is likely that this remains the case for the majority of other serotypes. The penetration of eggshells by Salmonella spp. has been reported under experimental conditions by many authors (Williams et al., 1968; Simmons et al., 1970; Sauter and Petersen, 1974; Gast and Beard, 1990; Padron, 1990; Humphrey et al., 1991; Fajardo et al., 1995; Schoeni et al., 1995; Miyamoto et al., 1998; Berrang et al., 1998; Wang and Slavik, 1998; Gast et al., 2006). Penetration can occur rapidly, for example, $S$. Typhimurium can penetrate the shell within 10 min of inoculation (Williams et al., 1968; Padron, 1990) although this occurred in only a small proportion of eggs (Williams et al., 1968).

Salmonella may more easily penetrate shells of eggs soon after they are laid. This may be due to the immaturity of the cuticle at the time of lay or the negative pressure developed in eggs during natural cooling may aid penetration (Padron, 1990; Miyamoto et al., 1998). Salmonella have been shown to penetrate the shells of eggs more rapidly when "hatchery conditions" were simulated (initial temperature of $35^{\circ} \mathrm{C}$ for $30 \mathrm{~min}$, followed by storage at $4{ }^{\circ} \mathrm{C}$ ) compared to incubation at $25{ }^{\circ} \mathrm{C}$ (Schoeni et al., 1995). The likelihood of penetration is also increased by condensation on shells (De Reu et al., 2006). In the UK and Ireland, Grade A eggs should not be chilled to temperatures below $5{ }^{\circ} \mathrm{C}$ during packing and distribution, and transportation should be free from excessive fluctuations in temperature (Anonymous, 2003b) to mini mise the temperature differences to which eggs are subjected.

Penetration is therefore most likely to occur immediately after lay, as the temperature of an egg equilibrates from the bird's body temperature $\left(42{ }^{\circ} \mathrm{C}\right)$ to ambient temperatures of around $20{ }^{\circ} \mathrm{C}$. The likelihood of penetration may also be increased at later stages in the distribution chain, if eggs are subject to environmental changes resulting in the formation of a temperature differential across the shell, or condensation.

Other factors may also influence shell penetration by Salmonella including serovar and shell quality (Sauter and Petersen, 1974). In particular the presence of microscopic cracks in shells greatly increases the incidence of internal contamination (Williams et al., 1968; Humphrey et al., 1989a; Perales and Audicana, 1989) and the likelihood of eggs being implicated in outbreaks (Todd, 1996). The rapid cooling of eggs increases the number and size of microscopic cracks (Fajardo, et al., 1995) and washing or cleaning can also damage the shell cuticle and increase internal contamination of eggs (Vadehdra et al., 1969). For this reason these processes may not be used for Grade A eggs. Cracked eggs were not considered in the current exposure assessment of Grade A shell eggs, which by definition must, in addition to meeting internal quality criteria, be clean and undamaged, and not be washed, cleaned or refrigerated below $5{ }^{\circ} \mathrm{C}$, (Anonymous, 2003b). In this assessment we also assume eggs found to be damaged at the time of preparation will be discarded, however we do not present any data to support this assumption.

Although the penetration of eggshells by Salmonella has been demonstrated experimentally, discrepancies in frequency of contam ination (De Buck et al., 2004) and serovars isolated from shells and egg contents (Humphrey, 1994; De Buck et al., 2004) provide strong evidence that penetration does not occur readily in practice. This argument, along with the low prevalence of shell contamination in eggs, indicate a low risk of Salmonella from the surface of eggs produced on the island of Ireland causing internal contamination during production and packing.

\subsubsection{Numbers of Salmonella in contaminated eggs}

The most available evidence suggests that internal egg contamina tion typically involves small initial numbers of $S$. Enteritidis. Studies of freshly laid eggs from experimentally inoculated hens found all positive samples of albumen and the majority (18/21) of yolk samples to contain fewer than $1 \mathrm{cfu} / \mathrm{ml}$ (Gast and Holt, 2000a) or a mean number of $5.5 \mathrm{cfu} / \mathrm{ml}$ contents (Gast and Beard, 1992); figures that for a $65 \mathrm{ml}$ egg, equate to less than $65 \mathrm{cfu}$ and 358 cfu per egg respectively.
The method of inoculation can significantly influence numbers of $S$. Enteritidis isolated (Gast et al., 2002). Studies of eggs produced by naturally infected birds have demonstrated even lower contamination levels, with $S$. Enteritidis numbers estimated at less than $10 \mathrm{cfu}$ per egg after 7 days (Humphrey et al., 1989a) and less than 20 cells after up to 21 days storage at room temperature (Humphrey et al., 1991). From these data the mean number of $S$. Enteritidis in eggs at time of lay was estimated as seven (Anonymous, 2002).

The initial contamination levels may be even lower than these figures suggest, as an increase of about $1 \log$ in $S$. Enteritidis numbers has been seen in the albumen of eggs, inoculated less than $24 \mathrm{~h}$ after lay (Gast and Holt, 2000b). In the first days following lay the $\mathrm{pH}$ of albumen increases from approximately 7.0 to 9.0, reducing iron availability and limiting growth (Humphrey, 1994; Cogan et al., 2001). No further increases in numbers are observed in these eggs, or in the albumen of older inoculated eggs, until a substantial period of storage has lapsed (Humphrey and Whitehead, 1993). Salmonella reported in eggs may represent the level attained after this growth, therefore numbers introduced at time of lay could be as low as only 1 or 2 cells (Cogan et al., 2001).

On occasion, naturally contaminated eggs with high numbers of Salmonella have been detected (Humphrey et al., 1991). This is likely due to the infrequent direct introduction of $S$. Enteritidis into yolks of eggs, or eggs subjected to time or temperature abuse, as has been reported for eggs implicated in outbreaks of salmonellosis (Humphrey et al., 1991).

\subsubsection{Deposition of internal contamination of Salmonella in eggs}

It is generally accepted that $S$. Enteritidis is initially limited to the albumen or the exterior of the vitelline membrane of the majority of eggs (Humphrey, 1994; Gast and Holt, 2001a; Anonymous, 2002). The majority of studies report the principal site for internal contamination to be the albumen (Gast and Beard, 1990; Shivasaprasad et al., 1990; Humphrey et al., 1991; Methner et al., 1995), but some studies have reported higher incidence of yolk contamination compared to albu men (Timoney et al., 1989; Gast and Holt, 2000a; Gast et al., 2002). However, where $S$. Enteritidis has been associated with the yolk, it is sometimes unclear whether this is attributable to contamination of yolk contents or the surrounding vitelline membrane. Studies that differentiate between isolation from yolk contents and whole yolk have shown contamination to be more often associated with the vitelline membrane than the interior contents (Gast and Beard, 1990; Gast and Holt, 2001a). For example, S. Enteritidis was recovered from $0.5 \%$ of yolk contents of eggs laid by experimentally infected hens, compared to $4.3 \%$ of the same eggs when both yolk and membrane were tested (Gast and Holt, 2001a).

The low number of cells present in the majority of eggs has been cited as further evidence that the initial deposition of $S$. Enteritidis in yolks happens only infrequently (Humphrey et al., 1991; Humphrey, 1994; Gast et al., 2006). Based on the data of Humphrey et al. (1991), that of 32 positive eggs none contained high numbers of Salmonella that would indicate yolk contamination, it was calculated that an average of $2.9 \%$ of Salmonella positive eggs would be yolk contami nated (Anonymous, 2002). The authors point out that this estimate is likely to be biased upwards, as it is based on data from only 32 eggs and disregards any prior expectation of the low prevalence of yolk contamination. Even though the initial deposition of $S$. Enteritidis in yolks is likely to be a rare event, it poses a greater risk to the public, as it can allow a rapid increase in $S$. Enteritidis numbers independent of changes to the albumen or yolk membrane normally necessary for the growth of Salmonella elsewhere in eggs.

\subsubsection{Growth of Salmonella in albumen}

Several studies have demonstrated that Salmonella can persist in the albumen of eggs (Lock and Board, 1992; Baron et al., 1997; Gast and Holt, 2000b; Gast and Holt, 2001b; Chen et al., 2005) although 
survival may be dependent on the serovar (Schoeni et al., 1995) and temperature of storage (Guan et al., 2006). Growth of S. Enteritidis in albumen has been reported in some studies (Clay and Board, 1991; Schoeni et al., 1995; Messens et al., 2004), although this has been shown to be highly sensitive to the numbers introduced (Clay and Board, 1991; Cogan et al., 2001). Where realistic inoculation levels are used, growth occurs only at low frequencies in keeping with those reported for naturally contaminated eggs (Humphrey, 1994; Cogan et al., 2001). Similarly, studies reporting heavy contamination of eggs after relatively brief storage times (Hammack et al., 1993; Schoeni et al., 1995; Braun and Fehlhaber, 1995) used an unrealistic inoculation level, and/or suspending media containing components that increase migration to the yolk membrane (Cogan et al., 2001).

It is widely accepted that, apart from an initial increase of $S$. Enteritidis in eggs observed up to $24 \mathrm{~h}$ post lay, no significant growth is seen in the majority of eggs until physical changes in albumen viscosity and the permeability of the yolk membrane enable bacterial movement and hence access to the yolk (Gast and Holt, 2001a). The likelihood of any Salmonella present in the albumen of eggs produced on the island of Ireland increasing in numbers during the production and processing module is therefore assessed as negligible.

\subsubsection{Summary}

The summary of the assessment for the production and packing module for eggs produced on the island of Ireland is:

- There is a low probability of shell contamination at the time of lay.

- Numbers of Salmonella on the surface of eggs are estimated to be low.

- There is a low likelihood of shell to shell cross contamination occurring during packing.

- The likelihood of any Salmonella present on a shell penetrating to the egg contents is low.

- There is a negligible probability of the albumen being contaminated with Salmonella at the time of lay; when it does occur numbers are low for the majority of eggs.

- There is a negligible probability of yolk contamination, but where yolk contamination occurs numbers of Salmonella can immediately increase to high levels, providing the storage temperature is conducive for growth.

- The likelihood of Salmonella present in albumen increasing during the production and packing module is negligible. Consequently, the assessed probabilities and numbers for Salmonella in albumen at the end of packing are equivalent to those at the time of lay, i.e. negligible and low respectively.

\subsection{Distribution and storage}

This module addresses changes in Salmonella contamination from the time eggs leave the packing site up to the point of preparation. This period covers the distribution of eggs to retail or wholesale establish ments, storage at this place of sale, transport to homes or catering establishments, and storage at the place of preparation. No changes in the prevalence of Salmonella contamination on or in eggs are expected during this module, as there is little opportunity for Salmonella transfer from shell to shell once eggs are packed. In addition, the distribution of eggs is governed by regulations so as to minimise conditions that favour shell penetration. Therefore the risk of Salmo nella from the surface of eggs causing internal contamination was judged as negligible.

\subsubsection{Yolk membrane integrity}

Growth of Salmonella in the majority of contaminated eggs is dependent on an increase in the permeability of the vitelline membrane, allowing bacteria in the albumen access to the yolk, and an environment conducive to growth. The three distinct phases seen in simulated growth curves for $S$. Enteritidis in eggs ( 10 fold increase in first $24 \mathrm{~h}$; lag phase of 34 weeks in the majority of eggs at $20^{\circ} \mathrm{C}$; exponential growth of $S$. enteritidis in an increasing proportion of inoculated eggs) can be explained in terms of yolk membrane integrity (Humphrey, 1994). The loss of membrane integrity depends on the time and temperature of storage. The main focus of this module is therefore on the effect of storage temperature on the breakdown of the yolk membrane, from the time eggs leave the packing site to the time they are prepared. Information on the timing and storage temperatures of egg distribution are not readily available in the published literature. Data have been estimated for the US and Canada from expert opinion and available evidence for the US and Canada (Anonymous, 2002), but these are not applicable to the UK and Ireland, as both US and Canada require the refrigeration of eggs throughout the distribution chain. For the purpose of this study, data for the duration and conditions of egg distribution were obtained from a limited number of egg processors and retailers in the island of Ireland. These, along with published surveys of consumer practice, were used to estimate the time and temperature inputs for this module.

\subsubsection{Distribution to point of sale}

The times and temperatures that eggs are subjected to may vary depending on the intended place of sale and/or place of preparation. Of UK eggs produced in 2006 29\% were processed, 23\% were destined for wholesale and the catering market, while the remaining $48 \%$ were sold at retail (Anonymous, 2007a). During transport from the packing station to supermarkets eggs are held at temperatures between 10 and $14{ }^{\circ} \mathrm{C}$; this distribution usually takes less than $24 \mathrm{~h}$ (Sainsbury PLC, pers. comm.). It has been estimated that in the UK $83 \%$ of eggs on retail sale are purchased through supermarkets (Anonymous, 2007a). Therefore the majority of eggs sold at retail on the island of Ireland are likely to be subjected to the conditions of transport described above, however there is little or no available information on the distribution of eggs to other points of purchase.

\subsubsection{Storage at point of sale}

All eggs must reach the final consumer within 21 days from their date of lay and the duration of storage at wholesale or retail should be limited by this requirement (Anonymous, 2004b). At supermarkets, the duration of storage from arrival at store to customer purchase is approximately $24 \mathrm{~h}$. During this time the temperature that eggs are subjected to may fluctuate but is estimated not to be above $20^{\circ} \mathrm{C}$ at any time (Sainsbury PLC, pers. comm.). Again, as supermarkets account for the majority of sales, these conditions will apply for a high proportion of eggs on retail sale. However, a study by Humphrey and Whitehead (1993) found that the temperature of eggs in one retail premise fluctuated between 18 and $30{ }^{\circ} \mathrm{C}$, and that eggs held to simulate these conditions often supported a rapid increase in S. Enteritidis after only 710 days storage.

\subsubsection{Transport to home or catering premises}

The time lapse from the point of purchase to the home is most likely to be of short duration. Two surveys, one for the island of Ireland (Kennedy et al., 2005) and one for the UK (Worsfold and Griffith, 1997a), reported journey times of less than 30 min for $58 \%$ and $90 \%$ of respondents respectively. However, considerable variations in trans port times were reported on the island of Ireland, with 35\% taking between 30 and $90 \mathrm{~min}, 6 \%$ taking $90 \mathrm{~min}$ to $3 \mathrm{~h}$ and a small percentage (1\%) over $3 \mathrm{~h}$. In the UK study, air temperatures recorded during the transport of food to the home ranged from 7.5 to $32{ }^{\circ} \mathrm{C}$. On this evidence it is unlikely that the storage conditions during this stage will greatly influence the level of contamination in eggs, particularly as eggs are not held under refrigerated conditions at retail sale, reducing the likelihood that condensation will occur during transport to point of preparation. 


\subsubsection{Storage in the home or catering premises}

Although current advice is for eggs to be stored in a refrigerator in original packaging (Anonymous, 2005b; Anonymous, 2003c), there are limited data on domestic and catering practices regarding the storage of eggs. In a UK survey of home caterers (caterers that prepare food from a domestic kitchen on a commercial basis), over $70 \%$ reported storing eggs in a refrigerator, and a further $23 \%$ stored eggs in a cool area such as in a cellar (Sin et al., 2000). Three other surveys found that eggs were stored in a refrigerator in approximately half of catering premises in the UK (Anonymous, 2007b; Elson et al., 2005; Taylor, 2004). In the most recent of these surveys of egg where the best before date could be determined, $10 \%$ were in use more than 21 days post lay, and $2 \%$ of eggs were past their best before date (28 days post lay) (Anonymous, 2007b). Taylor (2004) noted many caterers practiced good stock rotation that ensured eggs were used by their best before date, even though the surveyors considered that in many cases this was due to convenience rather than compliance with an informed policy. The short duration of storage of eggs in catering premises may somewhat offset the detrimental effects of being held at room temperature, but given the author's conclusion regarding lack of deliberation in these matters, this should not be relied upon.

A similar situation was reported for home consumers as for home caterers in the UK, with between 25 and 30\% of respondents storing eggs at room temperature (Parry et al., 2002). However a UK study based on direct observation of consumer behaviour found that $90 \%$ of subjects stored eggs in the refrigerator (Worsfold and Griffith, 1997b). This figure compares well with estimates of refrigerated storage of eggs of $93 \%$ in Finland (Lievonen et al., 2004) and 95\% in the US (Towns et al., 2006). In Finland, the majority (80\%) of stored eggs were within the best before date, and $65 \%$ of respondents reported the use of eggs no longer than 1 week after this date. However, $1.2 \%$ used eggs up to 2 months after the best before date (Lievonen et al., 2004). Based on this evidence growth of Salmonella is unlikely to occur during home storage in the substantial proportion of shell eggs which are stored at refrigerated temperatures and used within, or close to, their best before date. However, for a minority of eggs, storage at temperatures found in domestic kitchens $\left(17^{\circ} \mathrm{C}\right.$ to $23^{\circ} \mathrm{C}$; Evans et al., 1991) could allow significant increases of Salmonella in contaminated eggs, where the best before date is disregarded.

\subsubsection{Summary}

The summary of the assessment for the distribution and storage module is:

- The likelihood of Salmonella on a shell resulting in internal contamina tion is negligible, and as eggs are distributed packaged, there is limited chance for shell to shell contamination. Therefore the prevalence of Salmonella contamination on and in eggs remains low and negligible respectively throughout this module.

- Increases in Salmonella numbers are unlikely to be seen in the majority of contaminated eggs throughout their distribution to place of use. Numbers are not expected to increase on the shell of eggs, and the temperatures reported for these stages also preserve the yolk membrane integrity over their likely timeframe. The levels of contamination on the shell and in the albumen of eggs therefore remain low.

- In a small minority of cases where direct contamination of the yolk at lay occurred, numbers of Salmonella may increase to high levels during distribution if temperature is supportive to growth, and if numbers have not already reached this level.

- Increases in Salmonella numbers may also occur during storage at the place of preparation if eggs are stored at room temperature where the best before date is exceeded.

\subsection{Preparation and consumption}

\subsubsection{Cross contamination and preparation practices}

During the breaking of eggs, it has been shown that a small section of shell, estimated as $0.4 \mathrm{~cm}^{2}$, will come into contact with the egg contents (Braun et al., 2002). The number of $S$. Enteritidis transferred from a contaminated eggshell to food during preparation depends on the contamination level of the shell (Braun et al., 2002), but has been estimated as varying between 0 and 20 cells in an exposure assessment by Mokhtari et al. (2006). Given the low number of cells transferred, cross contamination from the shell is unlikely to lead to human infection unless followed by conditions that allow numbers to increase in foods.

Cross contamination of other foods has, however, often been implicated as a likely contributory factor in some outbreaks of salmonellosis (Gillespie et al., 2005). Eggs can act as a source of Sal monella that may be transferred to other foods via food preparers' hands, kitchen surfaces and utensils. In particular Salmonella can be distributed over work surfaces for some distance during the mixing of eggs (Humphrey et al., 1994). It is probable, however, that only heavily contaminated eggs would provide a substantial enough source of Salmonella to make this a likely exposure route. Again, where such cross contamination does occur, it is likely that numbers transferred would be low and so is of little consequence unless there is opportunity for further growth.

Irregular hand washing between the handling of meat and non meat foods has been associated with an increased risk of salmonellosis (Kohl et al., 2002) and a lower percentage (46.9\%) of case patients reported following safe procedures when handling eggs, compared to matched controls (62.5\%) (Mølbak and Neimann, 2002). A UK survey of home caterers found that over half of respondents reportedly washed their hands after handling intact eggs, and $45 \%$ after using raw egg contents. However, when the same subjects were asked at the start of the questionnaire to name foods that they washed their hands after handling, only $14 \%$ specified eggs (Sin et al., 2000). In another UK survey of hygienic practices in the home, $76 \%$ of respondents did not wash their hands after breaking eggs (Worsfold and Griffith, 1997b). Similarly, a recent study in Finland, found that $34 \%$ of respondents always washed their hands after handling eggs, $23 \%$ generally washed their hands, 35\% washed their hands if their fingers were sticky and 7\% reportedly did not wash their hands in any such situation (Lievonen et al., 2004). The authors of this study concluded that the low incidence of salmonellosis in Finland was likely not due to universal safe practice in the handling of eggs, but relied on the low prevalence of Salmonella infection in laying flocks.

\subsubsection{Salmonella growth during preparation}

There may be an opportunity for Salmonella growth during the preparation of food, but this will be dependent on the duration of preparation and the temperatures to which eggs and foods are subject. The probable temperature during preparation, of eggs previously stored in the refrigerator, was estimated at $10{ }^{\circ} \mathrm{C}$ (Mokhtari et al., 2006). At this temperature little or no growth of Salmonella in eggs is likely (Humphrey, 1990; Clay and Board, 1991; Schoeni et al., 1995; Chen et al., 2005). Numbers are therefore only likely to increase in eggs stored at ambient conditions prior to preparation, or where the preparation period is extended so eggs approach ambient tempera ture. The short preparation time before cooking, especially in domestic situations where durations of between 0 and $2 \mathrm{~h}$ are most likely (Mokhtari et al., 2006), limits the opportunity for growth. In catering situations this period may be extended, allowing for substantial increases in contamination levels, if eggs or foods are not refrigerated.

This risk may be compounded by the practice of pooling eggs during preparation and several outbreaks have been linked to time or temperature abuse of pooled eggs (St. Louis et al., 1988; Morris, 1990). Pooling refers to the combining of several eggs in a single mix, which is subsequently used for the preparation of multiple portions of a food. Pooling can increase the prevalence of egg contamination, as the addition of only one contaminated egg to the pool will result in the contamination of all portions of food prepared from that pool. Where 
pools are either cooked immediately, or held under conditions that restrict the growth of Salmonella, the practice can have a diluting effect, as the cells in a contaminated egg will be distributed throughout the mix.

The increased risk associated with this practice is proportional to the number of eggs used to prepare a pool (Morris, 1990). Therefore pooling is likely to have only a minor influence on the risk of disease transmission in a domestic setting where the numbers of eggs used are usually low. In catering situations, where greater numbers of eggs are involved, pooling can significantly increase the likelihood of Sal monella exposure, especially if followed by time or temperature abuse. Surveys of preparation practices in the UK (Anonymous, 2007b) and US (Lee et al., 2004) catering sectors found a high prevalence of unsafe egg preparation practices. In the UK $37 \%$ of all catering premises, and over $50 \%$ of institutional caterers, hotels and restaurants, reported pooling raw shell eggs not intended for immediate use. The number of eggs used to prepare a pool was fewer than 12 eggs in the majority (57.5\%) of establishments, while a third used 1236 eggs and 10\% used more than 36 eggs. Although the storage of prepared egg pools was reported to be of less than 2 h duration in the majority (81.6\%) of premises, storage times of 46 and over $6 \mathrm{~h}$ were reported by 4.1 and $4.6 \%$ of caterers respectively. Approximately half of establishments stored prepared pools at ambient temperatures (Anonymous, 2007b). In the US both the number of eggs used to prepare a pool and the time pools held before cooking depended on the menu item prepared. Average numbers used per pool ranged from 18 to 48 eggs, with average storage times of between 4 and $6 \mathrm{~h}$ at ambient temperature. A proportion of these restaurants also reported serving "runny" egg dishes (Lee et al., 2004). These practices, particularly when combined, substantially increase the risk of Salmonella exposure associated with egg consumption.

\subsubsection{Consumption patterns}

Certain food items have been specifically associated with cases of human salmonellosis; these include homemade desserts, ice cream and drinks containing raw eggs (Cowden et al., 1989a; Mølbak and Neimann, 2002); shop bought sandwiches containing mayonnaise or eggs (Cowden et al., 1989a), lightly cooked eggs (Cowden et al., 1989a) and eggs fried "sunny side up" (Mølbak and Neimann, 2002). No association was reported with other egg dishes such as soft boiled eggs (Cowden et al., 1989a; Mølbak and Neimann, 2002) and scrambled eggs (Mølbak and Neimann., 2002). Surveys of consump tion of raw and undercooked eggs have estimated overall prevalences of 18\% (Shiferaw et al., 2000), 19\% (Meer and Misner, 2000), 50\% (Klontz et al., 1995, Yang et al., 1998; Altekruse et al., 1999) and 56\% (Zhang et al., 1999). The differences in estimates may reflect differences in the way questions were asked, for example in the timescale considered, i.e. whether consumption had occurred in a limited time prior to questioning compared to the item ever having been consumed (Shiferaw et al., 2000).

A review of egg handling practices in the UK catering sector found that $90 \%$ of establishments reported serving eggs as meals, such as fried or boiled eggs and omelettes, and of these dishes $41 \%$ of premises reportedly never served them lightly cooked, while $48 \%$ sometimes served them lightly cooked, and 6\% always served them lightly cooked. In addition 26\% of premises served lightly cooked dishes containing eggs (Elson et al., 2005). Two further surveys of egg usage in Irish commercial catering premises (Anonymous, 1999b) and the UK catering industry (Taylor, 2004) reported widespread preparation of lightly cooked menu items, including in 100\% of nursing homes surveyed (Taylor, 2004). Elson et al. (2005) also found a proportion of catering establishments serving vulnerable groups prepared lightly cooked egg meals and foods containing eggs.

Raw egg dishes were reportedly served by $26 \%$ of Irish commercial catering premises. However approximately a third of these premises reported changing to the use of pasteurised eggs in raw and lightly cooked dishes, for reasons of safety (Anonymous, 1999b). The preparation of recipes containing raw eggs was also reported by $12 \%$ of restaurants and $8 \%$ of function caterers in one UK study (Taylor, 2004), by $3 \%$ of caterers in another (Elson et al., 2005) and by one in six of home caterers in a third (Sin et al., 2000). However, no nursing home (Taylor, 2004) or establishment serving vulnerable groups (Elson et al., 2005) reportedly served foods containing raw eggs. A Finnish study found that egg consumption patterns were correlated with subject age. Although the total egg consumption increased with increasing age the consumption of foods containing raw eggs decreased. The authors suggest that increased susceptibility, at least for this section of the population, may be offset by their food choices (Lievonen et al., 2004).

There are a few detailed studies of preparation and consumption patterns of eggs. Table 1 compares egg preparation pathways and the likelihood of each path as used in previous MRAs or estimated in consumer surveys (probabilities for Lievonen et al., 2004 and Mokhtari et al., 2006 calculated from the percentage of total eggs consumed as particular dishes). In all these studies the pathways differentiate between eggs consumed as egg meals (boiled, fried or scrambled eggs and omelettes) where they make up all or almost the entire dish, and other recipes where eggs constitute a smaller percentage of ingredients. This differentiation is made as the food product influences not only the percentage make up of eggs but also the amount of egg consumed per portion of the food.

Surveys and risk assessments also usually sub divide foods based on the degree to which they are cooked as this too influences the risk associated with their consumption. Generally three levels of cooking are used; well cooked, lightly cooked and raw (Lievonen et al., 2004; Mokhtari et al., 2006). The Health Canada MRA used these levels for eggs utilised as ingredients but specified boiling, scrambling or frying as categories for eggs served as meals. In the US MRA categories for well and lightly cooked egg meals, and cooked or raw foods containing eggs, were considered. From the evidence of these surveys and MRAs only a small proportion of eggs (less than $4 \%$ ) are consumed raw. However the studies estimated that a significant proportion of eggs are served undercooked, or as egg meals that are potentially served lightly cooked (Table 1 ).

\subsubsection{Effectiveness of cooking}

Egg associated outbreaks of Salmonella have been linked with the consumption of apparently well cooked eggs (Chantarapanont et al., 2000; Coyle et al., 1988). These outbreaks may have been caused by the re contamination of foods after cooking or by original contamina tion in eggs that survived the cooking process. One study has suggested that $S$. Enteritidis may be more heat resistant than some egg associated salmonellae (Humphrey et al., 1989b) while others report $S$. Enteritidis strains to have temperature sensitivities typical for the majority of Salmonella serovars (Morris, 1990). It is known that Salmonella spp. are significantly more resistant to heat when in egg yolk compared to albumen (Baker et al., 1983; Chantarapanont et al., 2000). Baker (1990) found scrambling to be the most effective cooking method for inactivating Salmonella in eggs, compared to poaching, boiling or frying. Of these cooking methods, boiling eggs required the longest cooking time $(7 \mathrm{~min})$ to achieve complete inactivation $\left(10^{4} \mathrm{cfu} / \mathrm{ml}\right)$ (Baker, 1990).

In other studies, boiling for over 6 to $10 \mathrm{~min}$ was required to inactivate approximately $10^{7} \mathrm{cfu} S$. Enteritidis in the yolk of shell eggs, depending on the method of boiling (eggs placed in water at $100{ }^{\circ} \mathrm{C}$ for up to $15 \mathrm{~min}$, compared to water at $23^{\circ} \mathrm{C}$, heating to $100^{\circ} \mathrm{C}$, removing from heat and holding for up to $15 \mathrm{~min}$ ), size and initial temperature of eggs (Chantarapanont et al., 2000; Humphrey et al., 1989b). At the same level of contamination, $S$. Enteritidis also survived in eggs fried "sunny side up" and "over easy", although it was only isolated after enrichment in the latter. S. Enteritidis was also isolated following enrichment from scrambled eggs cooked slowly but not when cooked 
Table 1

Summary of egg usage pathways in risk assessment studies

\begin{tabular}{|c|c|c|c|c|c|c|c|c|}
\hline Setting & Use & Pool & Cooking method/food & $\begin{array}{l}\text { Health Canada (from } \\
\text { Anonymous, 2002) }\end{array}$ & $\begin{array}{l}\text { Anonymous } \\
(1998)^{\mathrm{a}}\end{array}$ & $\begin{array}{l}\text { Anonymous } \\
(2002)^{\mathrm{a}}\end{array}$ & $\begin{array}{l}\text { Lievonen et al. } \\
(2004)^{\mathrm{b}}\end{array}$ & $\begin{array}{l}\text { Mokhtari et al. } \\
(2006)^{b}\end{array}$ \\
\hline Home & Egg & No & Raw & & & & 0.03 & \\
\hline Home & Egg & No & Lightly cooked & & 0.174 & & 0.105 & \\
\hline Home & Egg & No & Well cooked (hard boiled, fried) & & 0.337 & 0.443 & 0.469 & \\
\hline Home & Egg & No & Lightly cooked - fried & 0.186 & & 0.107 & & 0.31 \\
\hline Home & Egg & No & Lightly cooked - boiled/poached & 0.103 & & 0.0480 & & 0.19 \\
\hline Home & Egg & No & Lightly cooked - scrambled/omelette & & & 0.0633 & & \\
\hline Home & Egg & Yes & Raw & & & & & \\
\hline Home & Egg & Yes & Lightly cooked & & 0.0054 & & & \\
\hline Home & Egg & Yes & Well cooked & & 0.0104 & 0.00904 & & \\
\hline Home & Egg & Yes & Lightly cooked - fried & & & 0.00218 & & \\
\hline Home & Egg & Yes & Lightly cooked - boiled/poached & & & 0.000980 & & \\
\hline Home & Egg & Yes & Lightly cooked - scrambled/omelette & 0.124 & & 0.00129 & & 0.35 \\
\hline Home & Ingredient & No & Raw & 0.0068 & 0.0047 & 0.00147 & 0.009 & \\
\hline Home & Ingredient & No & Lightly cooked & 0.101 & & & 0.0035 & \\
\hline Home & Ingredient & No & $\begin{array}{l}\text { Well cooked (bakery products, casseroles, } \\
\text { mincemeat etc.) }\end{array}$ & 0.229 & 0.214 & 0.0720 & 0.375 & \\
\hline Home & Ingredient & Yes & $\begin{array}{l}\text { Raw (ice cream, eggnog, mayonnaise, salad } \\
\text { dressings, etc.) }\end{array}$ & & 0.0001 & 0.00003 & & 0.01 \\
\hline Home & Ingredient & Yes & Lightly cooked (custard, soufflé, lasagne etc.) & & & & & 0.05 \\
\hline Home & Ingredient & Yes & $\begin{array}{l}\text { Well cooked (cakes, muffins, bread, cookies } \\
\text { etc.) }\end{array}$ & & 0.0066 & 0.00147 & & 0.09 \\
\hline Caterer & Egg & No & Raw & & & & & \\
\hline Caterer & Egg & No & Lightly cooked & & 0.0547 & & & \\
\hline Caterer & Egg & No & Well cooked & & 0.106 & 0.143 & & \\
\hline Caterer & Egg & No & Lightly cooked - fried & 0.0825 & & 0.0346 & & \\
\hline Caterer & Egg & No & Lightly cooked - boiled/poached & 0.0014 & & 0.0155 & & \\
\hline Caterer & Egg & No & Lightly cooked - scrambled/omelette & & & 0.0205 & & \\
\hline Caterer & Egg & Yes & Raw & & & & & \\
\hline Caterer & Egg & Yes & Lightly cooked & & 0.0029 & & & \\
\hline Caterer & Egg & Yes & Well cooked & & 0.0057 & 0.00586 & & \\
\hline Caterer & Egg & Yes & Lightly cooked - fried & & & 0.00141 & & \\
\hline Caterer & Egg & Yes & Lightly cooked - boiled/poached & & & 0.000635 & & \\
\hline Caterer & Egg & Yes & Lightly cooked - scrambled/omelette & 0.0536 & & 0.000837 & & \\
\hline Caterer & Ingredient & No & Raw & 0.0023 & 0.0103 & 0.00712 & & \\
\hline Caterer & Ingredient & No & Lightly cooked & 0.0338 & & & & \\
\hline Caterer & Ingredient & No & Well cooked & 0.0765 & 0.0586 & 0.0166 & & \\
\hline Caterer & Ingredient & Yes & Raw & & 0.0013 & 0.00112 & & \\
\hline Caterer & Ingredient & Yes & Lightly cooked & & & & & \\
\hline Caterer & Ingredient & Yes & Well cooked & & 0.0073 & 0.00262 & & \\
\hline
\end{tabular}

a Average endpoint probabilities estimated in exposure assessments.

b Probabilities calculated from the percentage of total eggs consumed as particular dishes.

over a high heat. When contamination levels were over $10^{8} \mathrm{cfu}$ $S$. Enteritidis survived all the above forms of cooking (Humphrey et al., 1989b).

In a consumer phase risk assessment for Salmonella in eggs, thorough cooking was estimated to result in a 6 to $8 \log$ reduction of $S$. Enteritidis numbers in all categories of egg foods. For lightly cooked foods the reduction in numbers was judged to be dependent on the type of food involved, with $\log$ reductions ranging between 0 and 7 for fried eggs; for lightly cooked boiled and poached eggs the most likely reduction was estimated at only $1 \log$. No reduction was modelled for uncooked foods (Mokhtari et al., 2006).

\subsubsection{Storage after cooking}

Salmonella that survive the cooking process may be able to grow in foods which are not consumed immediately, or stored at refrigeration temperatures. Growth is again dependent on the time and tempera ture of storage, and the nature of the food product. In a study of consumer food preparation behaviour, $60 \%$ of subjects did not consume food immediately and most failed to cool it quickly; over half left food at ambient temperature for over $90 \mathrm{~min}$ and a small number (7\%) for over $6 \mathrm{~h}$ (mean holding time $2.1 \mathrm{~h}$ ) (Worsfold \& Griffith, 1997b). The duration of storage may be dependent on the type of food prepared. In a risk assessment for egg containing food products, the storage of egg meals was limited to less than $6 \mathrm{~h}$, while storage of foods containing raw and lightly cooked eggs was limited to $24 \mathrm{~h}$ (Mokhtari et al., 2006).
In the UK catering sector, the majority of premises (74\%) served lightly cooked foods immediately following preparation, but $47 \%$ of premises reported storing raw foods with eggs as ingredients after preparation. However, storage was often refrigerated; less than a quarter of premises stored lightly cooked foods, and an eighth stored uncooked foods, at temperatures above $8^{\circ} \mathrm{C}$ (Elson et al., 2005). No growth of Salmonella would be expected in foods stored in this way. Growth may also be inhibited by properties of the food, such as high salt or low water activity. Growth of Salmonella in some foods, such as bakery products (Mokhtari et al., 2006), is unlikely even when stored for longer periods at ambient temperature.

\subsubsection{Summary}

The summary of the assessment for the preparation and consumption module is:

- Based on the low prevalence of Salmonella on the surface of eggs at the time of preparation, there is a low likelihood of Salmonella from the shell contaminating the contents during the breaking of eggs.

- Low numbers of Salmonella transferred to egg contents from contaminated eggs shells during preparation; this will not increase the risk of exposure unless the food is subsequently subject to conditions that allow increases in contamination levels.

- Preparation times in domestic settings are short and growth of Salmonella during preparation is unlikely especially where eggs have been previously stored in the refrigerator. 
- In catering situations longer preparation times are possible increas ing the potential for Salmonella growth, however refrigeration can reduce the risk of this occurring.

- Pooling of eggs can increase the prevalence of contamination but is likely only to be of significance in catering situations where numbers of eggs used may be high.

- The majority of eggs are eaten well cooked and the thorough cooking of eggs reduces Salmonella in eggs to undetectable levels in the majority of instances.

- Although the effectiveness of cooking is dependent on the method used, the light cooking of eggs also reduces Salmonella numbers and may be sufficient to prevent exposure where contamination levels are low.

- Only a small percentage of eggs are likely to be consumed raw.

- Lightly cooked egg meals are generally served immediately follow ing preparation, allowing surviving Salmonella no opportunity to grow.

- Raw food may be stored following preparation, but storage of these foods is likely to be at refrigerated temperatures.

- Growth of Salmonella is inhibited by high salt content or low water activity found in many egg containing foods that are generally stored at room temperature for longer periods.

- Average weekly consumption of eggs on the island of Ireland is estimated as 1.8 eggs per person.

- Sections of the population with increased susceptibility to infection may be less likely to consume raw eggs, either by choice or by restrictions by food providers.

\section{Risk estimation}

The information collated for the three modules is qualified and combined to derive the probability and level of exposure as shown in Fig. 2. For the shell, there is a low probability of contamination at the time of lay and the probability remains at this level until the egg is used. Similarly, the number of organisms on the shell starts and remains low until it is used.

Although there is a negligible probability of the contents of eggs produced on the island of Ireland being contaminated at the time of lay, the final probability of the prepared serving being contaminated is low; the key factors influencing this "increase" are storage conditions enabling organisms from the shell to penetrate and enter into the contents, cross contamination from the shell during preparation, pooling and failure to inactivate the organism during cooking. If contaminated, numbers inside the egg start and remain low thus resulting in low numbers ingested.

\section{Discussion}

Neither qualitative nor quantitative MRAs for Salmonella have previously been developed for shell eggs produced on the island of Ireland. Previously published MRAs for Salmonella in eggs are based on information that is often specific to a particular region. The most recent of these studies (Anonymous, 2002) sought to provide a broader framework, for adaptation for use by different countries, but it too largely relies on data from the US and Canada.

\section{Shell \\ Probability of occurrence of Salmonella on shells at lay \\ Probability of cross contamination during packing \\ Probability of cross contamination during distribution}

Probability of cross contamination during storage at preparation site

Number of Salmonella at lay

Increase in numbers during packing

Increase in numbers during distribution

Increase in numbers during storage at preparation site

\section{Contents}

Probability of occurrence of Salmonella in contents at lay

Probability of shell penetration during packing

Probability shell penetration during distribution

Probability of shell penetration during storage at preparation site

Probability of cross contamination from shell during preparation

Probability of pooling with "other" contaminated eggs

Probability of survival at time of consumption

(including growth during and after preparation, inactivation during cooking)

Number of Salmonella at lay

Increase in numbers during packing

Increase in numbers during distribution

Increase in numbers during storage at preparation site

Number of Salmonella transferred from shell to egg-containing food during preparation

Additional organisms from contaminated pooled eggs

Proportion surviving at time of consumption

(including growth during and after preparation, inactivation during cooking)
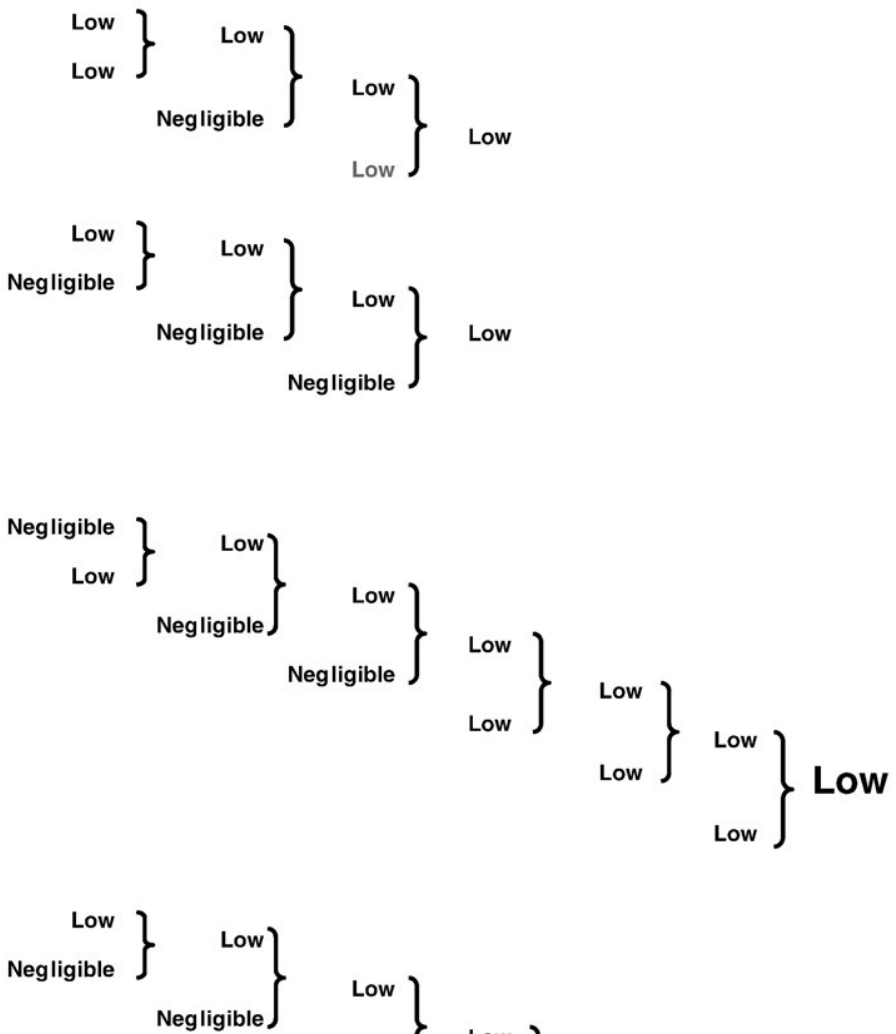

Low $\left.{ }_{\text {Low }}\right\}$

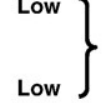

$\left.\begin{array}{c}\text { Low } \\ \text { Low }\end{array}\right\}$

Fig. 2. Qualitative assessment of stages in the exposure pathway for Salmonella in shell eggs. 
Previous MRAs provide quantitative assessments of the risk of exposure to Salmonella from shell eggs. However, for eggs produced on the island of Ireland a qualitative assessment was considered to be an appropriate approach, given the prevalence levels for Salmonella associated with shell eggs reported in a recent survey. The assessment is based on production and prevalence data for eggs produced on the island of Ireland, and therefore the risk from eggs imported from other EU member states to this region was not included in the model. The completion of this qualitative assessment has also provided an opportunity to evaluate the availability and suitability of data required in the development of MRA.

During the course of this assessment several areas where data for risk assessment is sparse were identified. In particular, Ireland specific data were difficult to source. For example, only limited data regarding the conditions and timing of stages in the distribution and storage module were available for the island of Ireland. This lack of data could have implications for the risk of exposure, given the dependence of Salmonella growth on temperature and duration of egg storage. Other factors for which region specific data were not available included prepara tion practices and consumption pathways for eggs. Much of the data for the consumption pathways of eggs relates to the situation in the US and Canada and the relevance of the data for the island of Ireland may therefore be questioned. The availability of data relating to the situation on the island of Ireland provides further argument for a qualitative rather than quantitative approach for the current assessment.

The qualitative framework presented here suggests that the risk of exposure to Salmonella from eggs produced on the island of Ireland is low. It should be noted though that this paper presents an exposure assessment, not a full risk assessment and therefore does not include an estimate of infection given exposure has occurred. It is therefore not valid to compare the low probability of exposure to reported case or outbreak statistics. This level of risk is strongly influenced by the low prevalence of contaminated eggs at the time of lay, as indicated by the survey of Murchie et al. (2007). Despite this initial low level, there are areas of the farm to consumption chain that result in increases in either the probability or level of contamination and thus if the prevalence at lay was to increase, the risk of exposure would be much higher. These areas are therefore worth addressing. In particular, several aspects of the preparation and consumption module suggest that the low incidence of egg associated salmo nellosis relies on the low prevalence of Salmonella in eggs rather than on adherence to safe preparation practices. For example, there is evidence of a lack of awareness of safe handling procedures for eggs in domestic settings. In catering establish ments the pooling of eggs not for immediate use continues to be a widespread practice, as is the preparation of lightly cooked food items.

The effect of Salmonella on the surface of shells has not been addressed in previous MRAs and data relating to this area are also lacking, including the enumeration on shells, and the likelihood of cross contamination of foods during preparation by Salmonella from shells. The higher prevalence of Salmonella on the shells compared to the contents of eggs suggests that this source of contamination may be of relatively greater importance. In this assessment shell contamination is one of the factors which influences a change from a negligible to low probability of content contamination, following shell penetration or cross contamination during preparation.

In conclusion, the qualitative assessment presented in this paper estimates a low risk of exposure to Salmonella from eggs produced on the island of Ireland. This assessment also highlights the importance of maintaining the current low prevalence of
Salmonella in eggs produced on the island of Ireland, given the dependence of consumer exposure on this factor.

\section{Acknowledgements}

This study was funded by safefood, the Food Safety Promotion Board, as project 03 RESR 005.

\section{References}

Alban, L., Olsen, A.M., Nielsen, B., Sørensen, R., Jessen, B., 2002. Qualitative and quantitative risk assessment for human salmonellosis due to multi-resistant Salmonella typhimurium DT104 from consumption of Danish dry-cured pork sausages. Preventative Veterinary Medicine 52, 251-265.

Altekruse, S.F., Yang, S., Timbo, B.B., Angulo, F.J., 1999. A multi-state survey of consumer food-handling and food-consumption practices. American Journal of Preventative Medicine 16, 216-221.

Anonymous, 1996. S.I. No 2/1996. European Communities (Zoonoses) Regulations. Available at: http://www.irishstatutebook.ie/ZZSI2Y1996.html Accessed 11 October 2006.

Anonymous, 1998. Salmonella enteritidis Risk Assessment. Shell Eggs and Egg Products. Final Report. Prepared for FSIS by the Salmonella enteritidis Risk assessment Team. Available as PDF at: http://www.fsis.usda.gov/ophs/risk/Accessed 20 March 2008.

Anonymous, 1999a. Principles and guidelines for the conduct of microbial risk assessment CAC/GL-30. Codex Alimentarius Commission. FAO, Rome Italy.

Anonymous, 1999b. Survey of Egg Usage in the Irish Hotel, Restaurant and Commercial Catering Industry, May 1999. Food Safety Authority of Ireland. Available at: http:// www.fsai.ie/publications/other/1999egg_survey.pdf Accessed 20 March 2008.

Anonymous, 2001. Second report on Salmonella in eggs. Advisory Committee on the Microbiological Safety of Food. HMSO, London, UK.

Anonymous, 2002. Risk assessments of Salmonella in eggs and broiler chickens. Microbiological risk assessment series 2. World Health Organization, Geneva, Switzerland; Food and Agriculture Organization of the United Nations, Rome, Italy.

Anonymous, 2003a. Results of Third Quarter National Survey 2003 (03NS3) bacteriological safety of eggs produced under the Bord Bia Egg Quality Scheme (EQAS). Food Safety Authority of Ireland, Dublin, Ireland. Available at: http://www.fsai.ie surveillance/food_safety/microbiological/eggs_bacteriological.pdf Accessed 18 March 2008.

Anonymous, 2003b. Commission regulation (EC) no. 2295/2003 of 23 December 2003. Introducing Detailed Rules for Implementing Council Regulation (EEC) No 1907/90 on Certain Marketing Standards for Eggs. Available at: http://europa.eu.int/eur-lex/ en/consleg/pdf/2003/en_2003R2295_do_001.pdf Accessed 21 February 2007.

Anonymous, 2003c. Eggs - what caterers need to know. I5 January 2003. Food Standards Agency. Available at: http://www.food.gov.uk/multimedia/pdfs/eggleaflet.pdf Accessed 20 March 2008.

Anonymous, 2004a. Report of the survey of Salmonella contamination of UK produced shell eggs on retail sale. Food Standards Agency. HMSO, London, UK. Available at: http://www.food.gov.uk/science/surveillance/fsis2004branch/fsis5004eggs Accessed 20 March 2008

Anonymous, 2004b. Commission regulation (EC) No 853/2004 of the European Parliament and of the council of 29 April 2004 laying down specific hygiene rules on the hygiene of foodstuffs. Official J. European Communities L139, 55-205.

Anonymous, 2005a. Summary of Lion Quality Code of Practice. British Egg Industry Council. BEIS, London, UK. Available at: http://www.britegg.co.uk/lionquality05/ startlionquality.html Accessed 18 March 2008.

Anonymous, 2005b. Egg Safety. British Egg Industry Council. BEIS, London, UK. Available at: http://www.britegg.co.uk/safety05/startsafety.html Accessed 20 March 2008.

Anonymous, 2006a. Annual Data Table Salmonella. Health Protection Scotland, Glasgow, UK. Available at: http://www.documents.hps.scot.nhs.uk/giz/10-year-tables/salmonella.pdf Accessed 20 March 2008

Anonymous, 2006b. Laboratory reports of Salmonella enteritidis 1995-2006. Northern Ireland. Communicable Disease Surveillance Centre Northern Ireland, Belfast, UK. Available at: http://www.cdscni.org.uk/surveillance/Gastro/Salmonella_enteritidis. htm Accessed 20 March 2008.

Anonymous, 2006c. Salmonella enteritidis in humans, faecal and lower gastrointestinal tract isolates, England and Wales, 1981-2005. Health Protection Agency, London, UK. Available at: http://www.hpa.org.uk/infections/topics_az/salmonella/data_human_se.htm Accessed 20 March 2008.

Anonymous, 2007a. UK eggs. BEIS facts \& figures. British Egg Information Service. Available at: http://www.britegg.co.uk/ukeggs05/ukeggs4.html Accessed 20 March 2008.

Anonymous, 2007b. UK wide survey of Salmonella in raw shell eggs used in catering premises. Final Report. Food Standards Agency. Available at: http://www.food.gov. uk/multimedia/pdfs/eggsurvey2007.pdf Accessed 20 March 2008.

Baker, R.C., 1990. Survival of Salmonella enteritidis on and in shelled eggs, liquid eggs and cooked egg products. Dairy Food and Environmental Sanitation 10, 273-275.

Baker, R.C., Hogarty, S., Poon, W., 1983. Survival of Salmonella typhimurium and Staphylococcus aureus in eggs cooked by different methods. Poultry Science 62, $1211-1216$.

Baron, F., Gautier, M., Brule, G., 1997. Factors involved in the inhibition of growth of Salmonella enteritidis in liquid egg white. Journal of Food Protection 60, 1318-1323.

Berrang, M.E., Frank, J.F., Buhr, R.J., Bailey, J.S., Cox, J.M., Mauldin, J., 1998. Eggshell characteristics and penetration by Salmonella through the productive life of a broiler breeder flock. Poultry Science 77, 1446-1450. 
Bradshaw, J.G., Shah, D.B., Forney, E., Madden, J.M., 1990. Growth of Salmonella enteritidis in yolk of shell eggs from normal and seropositive hens. Journal of Food Protection 53, 1033-1036.

Braun, P., Fehlhaber, K., 1995. Migration of Salmonella enteritidis from the albumen into the egg yolk. International Journal of Food Microbiology 25, 95-99.

Braun, P., Mayer, K., Fehlhaber, K., 2002. Breaking procedure as an important way of contamination of the liquid egg product with Salmonella enteritidis. Archiv für Lebensmittelhygiene 53,124-126.

Chantarapanont, W., Slutsker, L., Tauxe, R.V., Beuchat, L.R., 2000. Factors influencing inactivation of Salmonella enteritidis in hard-cooked eggs. Journal of Food Protection $63,36-43$.

Chen, J., Shallo Tesmar, H., Kerr, W.L., 2005. Outgrowth of salmonellae and the physical property of albumen and vitelline membrane as influenced by egg storage conditions. Journal of Food Protection 68, 2553-2558.

Clay, C.E., Board, R.G., 1991. Growth of Salmonella enteritidis in artificially contaminated hen's shell eggs. Epidemiology and Infection 106, 271-281.

Clough, H.E., Clancy, D., French, N.P., 2006. Vero-cytotoxigenic Escherichia coli 0157 in pasteurized milk containers at the point of retail: A qualitative approach to exposure assessment. Risk Analysis 26, 1291-1309.

Cogan, T.A., Domingue, G., Lappin-Scott, H.M., Benson, C.E., Woodward, M.J., Humphrey, T.J., 2001. Growth of Salmonella enteritidis in artificially contaminated eggs: The effects of inoculum size and suspending media. International Journal of Food Microbiology 70, 131-141.

Cogan, T.A., Humphrey, T.J., 2003. The rise and fall of Salmonella enteritidis in the UK Journal of Applied Microbiology 94, 114S-119S.

Cowden, J.M., Chisholm, D., O'Mahony, M., Mawer, S.L., Spain, G.E., Ward, L., Rowe, B., 1989a Two outbreaks of Salmonella enteritidis phage type 4 infection associated with the consumption of fresh shell-egg products. Epidemiology and Infection 103, 47-52.

Cowden, J.M., Lynch, D., Joseph, C.A., O'Mahony, M., Mawer, S.L., Rowe, B., Bartlett, C.L, 1989b. Case-control study of infections with Salmonella enteritidis phage type 4 in England. British Medical Journal 299, 771-773.

Coyle, E.F., Palmer, S.R., Ribeiro, C.D., Jones, H.I., Howard, A.J., Ward, L., Rowe, B., 1988 Salmonella enteritidis phage type 4 infection: Association with hens' eggs. Lancet 332 (8623), 1295-1297.

Davies, R., Breslin, M., 2004. Observations on Salmonella contamination of eggs from infected commercial laying flocks where vaccination for Salmonella enterica serovar Enteritidis had been used. Avian Pathology 33,133-144.

De Buck, J., Van Immerseel, F., Ducatelle, R., 2004. Colonization of the chicken reproductive tract and egg contamination by Salmonella. A review. Journal of Applied Microbiology 97, 233-245.

de Louvois, J., 1993a. Salmonella contamination of eggs. Lancet 342 (8867), 366-367.

de Louvois, J., 1993b. Salmonella contamination of eggs: A potential source of human salmonellosis. PHLS Microbiology Digest 10, 158-162.

De Reu, K., Grijspeerdt, K., Heyndrickx, M., Messens, W., Uyttendaele, M., Debevere, J., Herman, L., 2006. Influence of eggshell condensation on eggshell penetration and whole egg contamination with Salmonella enterica serovar Enteritidis. Journal of Food Protection 69, 1539-1545.

Elson, R., Little, C.L., Mitchell, R.T., 2005. Salmonella and raw shell eggs: Results of a cross-sectional study of contamination rates and egg safety practices in the United Kingdom catering sector in 2003. Journal of Food Protection 68, 256-264.

Evans, G.I., Stanton, J.L., Russell, S.L., James, S.J., 1991. Consumer Handling of Chilled Foods: A Survey of Time and Temperature Conditions. MAFF London.

Fajardo, TA., Anantheswaran, R.C., Puri, V.M, Knabel, S.J., 1995. Penetration of Salmonella enteritidis into eggs subjected to rapid cooling. Journal of Food Protection 58, 473-477.

Foyle, B., McKeown, P., Doran, G., Cormican, M., 2004. Annual report on Salmonella in Ireland, 2004. National Disease Surveillance Centre, Dublin, Ireland. Available at: http://www.ndsc.ie/hpsc/A-Z/Gastroenteric/Salmonellosis/Publications/File,1461, en.pdf Accessed 20 March 2008.

Gast, R.K., Beard, C.W., 1990. Production of Salmonella enteritidis-contaminated eggs by experimentally infected hens. Avian Diseases 34, 438-446.

Gast, R.K., Beard, C.W., 1992. Detection and enumeration of Salmonella enteritidis in fresh and stored eggs laid by experimentally infected hens. Journal of Food Protection 55, 152-156.

Gast, R.K., Guard-Petter, J., Holt, P.S., 2002. Characteristics of Salmonella enteritidis contamination in eggs after oral, aerosol, and intravenous inoculation of laying hens. Avian Diseases 46, 629-635.

Gast, R.K., Holt, P.S., 2000a. Deposition of phage type 4 and 13a Salmonella enteritidis strains in the yolk and albumen of eggs laid by experimentally infected hens. Avian Diseases 44, 706-710.

Gast, R.K., Holt, P.S., 2000b. Influence of the level and location of contamination on the multiplication of Salmonella enteritidis at different storage temperatures in experimentally inoculated eggs. Poultry Science 79, 559-563.

Gast, R.K., Holt, P.S., 2001a. Assessing the frequency and consequences of Salmonell enteritidis deposition on the egg yolk membrane. Poultry Science 80, 997-1002.

Gast, R.K., Holt, P.S., 2001b. Multiplication in egg yolk and survival in egg albumen of Salmonella enterica serotype Enteritidis strains of phage types 4, 8,13a, and 14b. Journal of Food Protection 64, 865-868.

Gast, R.K., Holt, P.S., Guraya, R., 2006. Effect of refrigeration on in vitro penetration of Salmonella enteritidis through the egg yolk membrane. Journal of Food Protection $69,1426-1429$.

Gillespie, I.A., O'Brien, S.J., Adak, G.K., Ward, L.R., Smith, H.R., 2005. Foodborne general outbreaks of Salmonella enteritidis phage type 4 infection, England and Wales, 1992-2002: Where are the risks? Epidemiology and Infection 133 795-801.

Guan, J., Grenier, C., Brooks, B.W., 2006. In vitro of Salmonella enteritidis and Salmonella typhimurium definitive type 104: Survival in egg albumen and penetration throug the vitelline membrane. Poultry Science 85, 1678-1681.
Hammack, T.S., Sherrod, P.S., Verneal, R., Bruce, G.A., Satchell, F.B., Andrews, W.H., 1993 Growth of Salmonella enteritidis in grade A eggs during prolonged storage. Poultry Science 71, 373-377.

Hope, B.K., Baker, R., Edel, E.D., Hogue, A.T., Schlosser, W.D., Whiting, R., McDowell, R.M. Morales, R.A., 2002. An overview of the Salmonella enteritidis risk assessment for shell eggs and egg products. Risk Analysis 22, 203-218.

Humphrey, T.J., 1990. Growth of Salmonella in intact shell eggs: Influence of storage temperature. Veterinary Research 126, 292

Humphrey, T.J., 1994. Contamination of egg shell and contents with Salmonella enteritidis: A review. International Journal of Food Microbiology 21, 31-40.

Humphrey, T.J., Baskerville, A., Mawer, S., Rowe, B., Hopper, S., 1989a. Salmonella enteritidis phage type 4 from the contents of intact eggs: A study involving naturally infected hens. Epidemiology and Infection 103, 415-423.

Humphrey, T.J., Greenwood, M., Gilbert, R.J., Rowe, B., Chapman, P.A., 1989b. The survival of salmonellas in shell eggs cooked under simulated domestic conditions. Epidemiology and Infection 103, 35-45.

Humphrey, T.J., Martin, K.W., Whitehead, A., 1994. Contamination of hands and work surfaces with Salmonella enteritidis PT4 during the preparation of egg dishes. Epidemiology and Infection 113, 403-409.

Humphrey, T.J., Whitehead, A., 1993. Egg age and the growth of Salmonella enteritidis in egg contents. Epidemiology and Infection 111, 209-219.

Humphrey, T.J., Whitehead, A., Gawler, A.H.L., Henley, A., Rowe, B., 1991. Numbers of Salmonella enteritidis in the contents of naturally contaminated hens' eggs. Epidemiology and Infection 106, 489-496.

Kennedy, J., Jackson, V., Blair, I.S., McDowell, D.A., Cowan, C., Bolton, D.J., 2005. Food safety knowledge of consumers and the microbiological and temperature status of their refrigerators. Journal of Food Protection 68, 1421-1430.

Klontz, K.C., Timbo, B., Fein, S., Levy, A., 1995. Prevalence of selected food consumption and preparation behaviours associated with increased risks of food-borne disease. Journal of Food Protection 58, 927-930.

Kohl, K.S., Rietberg, K., Wilson, S., Farley, T.A., 2002. Relationship between home foodhandling practices and sporadic salmonellosis in adults in Louisiana, United States. Epidemiology and Infection 129, 267-276.

Lee, R., Beatty, M.E., Bogard, A.K., Esko, M.P., Angulo, F.J., Selman, C., 2004. Prevalence of high-risk egg-preparation practices in restaurants that prepare breakfast egg entrées: An EHS-Net study. Journal of Food Protection 67, 1444-1450.

Lievonen, S., Havulinna, A.S., Maijala, R., 2004. Egg consumption patterns and Salmonella risk in Finland. Journal of Food Protection 67, 2416-2423.

Lock, J.L., Board, R.G., 1992. Persistence of contamination of hens' egg albumen in vitro with Salmonella serotypes. Epidemiology and Infection 108, 389-396.

Mawer, S.L., Spain, G.E., Rowe, B., Humphrey, T.J., Cruickshank, J.G., 1989. Salmonella enteritidis phage type 4 and hens' eggs (letter). Lancet 333, 280-281.

Meer, R.P., Misner, S.L., 2000. Food safety knowledge and behavior of expanded food and nutritional education program participants in Arizona. Journal of Food Protection $63,1725-1731$

Messens, W., Duboccage, L., Grijspeerdt, K., Heyndrickx, M., Herman, L., 2004. Growth of Salmonella serovars in hens' egg albumen as affected by storage prior to inoculation. Food Microbiology 21, 25-32.

Messens, W., Grijspeerdt, K., Herman, L., 2006. Eggshell penetration of hens' eggs by Salmonella enterica serovar Enteritidis upon various storage conditions. British Poultry Science 47, 554-560.

Methner, U., al-Shabibi, S., Meyer, H., 1995. Experimental oral infection of specific pathogen-free laying hens and cocks with Salmonella enteritidis strains. Journal of Veterinary Medicine 42, 459-469.

Miyamoto, T., Horie, T., Baba, E., Sasai, K., Fukata, T., Arakawa, A., 1998. Salmonella penetration through eggshell associated with freshness of laid eggs and refrigeration. Journal of Food Protection 61, 350-353.

Mokhtari, A., Moore, C.M., Yang, H., Jaykus, L.A., Morales, R., Cates, S.C., Cowden, P., 2006. Consumer-phase Salmonella enterica serovar Enteritidis risk assessment for eggcontaining food products. Risk Analysis 26, 753-768.

Mølbak, K., Neimann, J., 2002. Risk factors for sporadic infection with Salmonella enteritidis, Denmark, 1997-1999. American Journal of Epidemiology 156, 654-661.

Morris, G.K., 1990. Salmonella enteritidis and eggs: Assessment of risk. Dairy, Food and Environmental Sanitation 10, 279-281.

Moutou, F., Dufour, B., Ivanov, Y., 2001. A qualitative assessment of the risk of introducing foot and mouth disease into Russia and Europe from Georgia, Armenia and Azerbaijan. Revue scientifique et technique (International Office of Epizootics) 20, 723-730.

Murchie, L., Whyte, P., Xia, B., Horrigan, S., Kelly, L., Madden, R., 2007. Prevalence of Salmonella in grade A whole shell eggs in the island of Ireland. Journal of Food Protection 70,1238-1240.

Musgrove, M.T., Jones, D.R., Northcutt, J.K., Harrison, M.A., Cox, N.A., 2005. Impact of commercial processing on the microbiology of shell eggs. Journal of Food Protection $68,2367-2375$.

Okamura, M., Kamijma, Y., Miyamoto, T., Tani, H., Sasai, K., Baba, E., 2001. Difference among six Salmonella serovars in abilities to colonize reproductive organs and to contaminate eggs in laying hens. Avian Diseases 45, 61-69.

Oscar, T.P., 2004. A quantitative risk assessment model for Salmonella and whole chickens. International Journal of Food Microbiology 93, 231-247.

Padron, M., 1990. Salmonella typhimurium penetration through the eggshell of hatching eggs. Avian Diseases 34, 463-465.

Parry, S.M., Palmer, S.R., Slader, J., Humphrey, T., 2002. Risk factors for salmonella food poisoning in the domestic kitchen - a case control study. Epidemiology and Infection 129, 277-285.

Paul, J., Batchelor, B., 1988. Salmonella enteritidis phage type 4 and hens' eggs. Lancet 332 (8625), 1421. 
Perales, I., Audicana, A., 1989. The role of hens' eggs in outbreaks of salmonellosis in north Spain. International Journal of Food Microbiology 8, 175-180.

Radkowski, M., 2002. Effect of moisture and temperature on survival of Salmonella enteritidis on shell eggs. Archiv für Geflügelkunde 66, 119-123.

Rizk, S.S., Ayres, J.C., Kraft, A.A., 1966. Effect of holding condition on the development of Salmonellae in artificially inoculated hens' eggs. Poultry Science 45, 825-829.

Rodrigue, D.C., Tauxe, R.V., Rowe, B., 1990. International increase in Salmonella enteritidis: a new pandemic? Epidemiology and Infection 105, 21-27.

Sauter, E.A., Petersen, C.F., 1974. The effect of egg shell quality on penetration by various salmonellae. Poultry Science 53, 2159-2162.

Schoeni, J.L., Glass, K.A., McDermott, J.L., Wang, A.C., 1995. Growth and penetration of Salmonella enteritidis, Salmonella heidelberg and Salmonella typhimurium in eggs. International Journal of Food Microbiology 24, 385-396.

Shiferaw, B., Yang, S., Cieslak, P., Vugia, D., Marcus, R., Koehler, J., Deneen, V., Angulo, F., 2000. Prevalence of high-risk food consumption and food-handling practices among adults: A multistate survey, 1996 to 1997. Journal of Food Protection 63, 1538-1543.

Shivasaprasad, H.L., Timoney, J.F., Morales, S., Lucio, B., Baker, R.C., 1990. Pathogenesis of Salmonella enteritidis infection in laying chickens. I. Studies on egg transmission, clinical signs, fecal shedding, and serologic responses. Avian Diseases 34, 548-557.

Simmons, E.R., Ayres, J.C., Kraft, A.A., 1970. Effect of moisture and temperature on ability of Salmonella to infect shell eggs. Poultry Science 49, 761-768.

Sin, J., Quigley, C., Davies, M., 2000. Survey of raw egg use by home caterers. Communicable Disease and Public Health 3, 90-94.

St Louis, M.E, Morse, D.L, Potter, M.E., DeMelfi, T.M., Guzewich JJ. Tauxe, R.V, Blake, P.A., 1988. The emergence of grade A eggs as a major source of Salmonella enteritidis infections. New implications for the control of salmonellosis. Journal of the American Medical Association 259, 2103-2107.

Taylor, E., 2004. Investigating safe egg use in the catering industry. A pilot study to estimate the nature and extent of adherence to government guidance. British Food Journal 106, 808-818.

Timoney, J.F., Shivaprasad, H.L., Baker, R.C., Rowe, B., 1989. Egg transmission after infection of hens with Salmonella enteritidis phage type 4. Veterinary Record 125, 600-601.
Todd, E.C., 1996. Risk assessment of use of cracked eggs in Canada. International Journal of Food Microbiology 30, 125-143.

Towns, R.E., Cullen, R.W., Memken, J.A., Nnakwe, N.E., 2006. Food safety-related refrigeration and freezer practices and attitudes of consumers in Peoria and surrounding counties. Journal of Food Protection 69, 1640-1645.

Vadehdra, D.V., Baker, R.C., Naylor, H.B., 1969. Salmonella infection of cracked eggs. Poultry Science 48, 954-957.

Wang, H., Slavik, M.F., 1998. Bacterial penetration into eggs washed with various chemicals and stored at different temperatures and times. Journal of Food Protection 61, 276-278.

Whiting, R.C., Buchanan, R.L., 1997. Development of a quantitative risk assessment model for Salmonella enteritidis in pasteurized liquid eggs. International Journal of Food Microbiology 36, 111-125.

Whiting, R.C., Hogue, A., Schlosser, W.D., Ebel, E.D., Morales, R.A., Baker, A., McDowell, R.M., 2000. A quantitative process model for Salmonella enteritidis in shell eggs. Journal of Food Science 65, 864-869.

Williams, J.E., Dillard, L.H., Hall, G.O., 1968. The penetration patterns of Salmonella typhimurium through the outer structures of chicken eggs. Avian Disease 12 $445-466$.

Worsfold, D., Griffith, C.J., 1997a. Assessment of the standard of consumer food safety behaviour. Journal of Food Protection 60, 399-406.

Worsfold, D., Griffith, C.J., 1997b. Food safety behaviour in the home. British Food Journal 99, 97-104.

Yang, S., Leff, M.G., McTague, D., Horvath, K.A., Thompson, J., Murayi, T., Boeselager, G.K., Melruk, T.A., Gildmaster, M.C., Ridings, D.L., Altekruse, S.F., Angulo, F.., 1998. Multistate surveillance for food handling and preparation and consumption behaviours associated with foodborne diseases 1995 and 1996. Morbidity and. Mortality Weekly Report 47, 33-54.

Zhang, P., Penner, K., Johnston, J., 1999. Prevalence of selected unsafe food-consumption practices and their associated factors in Kansas. Journal of Food Safety 19, 289-297. 